\title{
Psychobiology of Mindfulness
}

\author{
By Dan J. Stein, MD, PhD, Victoria Ives-Deliperi, MA, \\ and Kevin G.F. Thomas, PhD
}

\begin{abstract}
There is controversy about whether mindfulness-based approaches to psychotherapy represent a new wave of cognitive-behavioral therapy or a core process in all psychotherapies. One way of conceptualizing mindfulness is in terms of emotion regulation; mindfulness is a strategy aimed at opposing suppression and avoidance. Dispositional mindfulness has been associated with greater activation in prefrontal cortex and greater deactivation of amygdala during affect labeling. A number of rigorous studies of mindfulness-based cognitive therapy for depression have been positive. However, much remains to be discovered about the underlying mechanisms of and clinical indications for mindfulness-based approaches.
\end{abstract}

\section{CASE REPORT}

Steve is a 24-year-old student who had experienced episodes of recurrent depression. He had various options for graduate school and was concerned about whether his choice would be a meaningful one. All too often, he was pessimistic about the future, and concerned that graduate school was the first step toward a life of unhappiness. Initially, Steve's therapist used mindfulness-based stress reduction techniques, which provided some short-term alleviation of his emotional distress. These techniques were consistent with previous readings he had done on the importance of self-acceptance and selfdiscovery. Over time, his therapist began challenging his worldviews more aggressively, and he gradually began to see graduate school as an exciting step into the next phase of his life.

\section{COGNITIVE-AFFECTIVE NEUROSCIENCE}

Mindfulness is a construct with a long and rich history; it is not a unitary phenomenon, and there is ongoing work on optimal operational definition. ${ }^{1-3}$ As an initial step, mindfulness has been described in terms of sustained and non-evaluative moment-to-moment awareness and attention to perceptible mental states and processes, including sensations, feelings, and thoughts. ${ }^{4}$ Mindfulness is thought to play a key role in meditation practices. ${ }^{5}$

One way of understanding mindfulness is in terms of emotional regulation. Gross ${ }^{6,7}$ has divided emotional regulation into antecedent-focused and response-focused strategies. Antecedent-focused emotional-regulation strategies include situation modification and cognitive reframing. Response-focused emotional-regulation strategies include suppression and experiential avoidance strategies.

\footnotetext{
Dr. Stein is professor in and chair of the Department of Psychiatry and Mental Health at the University of Cape Town in South Africa, and is also on faculty at the Mount Sinai School of Medicine in New York City. Ms. Ives-Deliperi is a doctoral student and Dr. Thomas is senior lecturer, both in the Department of Psychology at the University of Cape Town.

Faculty Disclosures: Dr. Stein has received grant support/honoraria from AstraZeneca, Eli Lilly, GlaxoSmithKline, Lundbeck A/S, Orion, Pfizer, Pharmacia, Roche, Servier, Solvay, Sumitomo, and Wyeth. Ms. Ives-Deliperi and Dr. Thomas do not have an affiliation with or financial interest in any organization that might pose a conflict of interest.

Funding/Support: Dr. Stein receives support from the Medical Research Council of South Africa.

Authors' note: This case is based on an amalgam of the authors' experience.
} 
Mindfulness is one such strategy as it opposes suppression and avoidance. ${ }^{8}$

A key mechanism for increasing mindfulness is the labeling of aspects of experience. Labeling emotions, for example, may allow recognition of, distancing from, and regulation of affective experience. ${ }^{5}$ Thus, a cognitivebehavioral mindfulness-meditation intervention (mindfulness-based cognitive therapy) encourages the use of words or phrases to label emotional states. ${ }^{9}$ However, meditative practices may use a range of different approaches, ${ }^{10}$ and the mechanisms underlying mindfulness require further investigation. ${ }^{11}$

\section{Neuroanatomy/Neurochemistry}

Emotional regulation appears to be accompanied by increased activation in prefrontal cortex (PFC) and/or decreased activation in regions such as the amygdala and insula. ${ }^{12}$ Failure of emotional regulation may play a key role in anxiety ${ }^{13}$ and in depression. ${ }^{14}$ On the other hand, dorsolateral PFC may be important in conscious reframing and control of external behavioral processes, while ventromedial PFC and orbitofrontal cortex may be particularly important in emotion evaluation and control of internal states. ${ }^{15-17}$

Verbal labeling of affective stimuli has been studied during imaging. Affect labeling activates right ventrolateral PFC (RVLPFC) and attenuates responses in amygdala (Figure 1). ${ }^{18-}$ ${ }^{20}$ This process may disrupt automatic affective responses and lead to a decrease in their intensity or duration; indeed, imaging correlates of emotional regulation have been associated with more adaptive diurnal cortisol patterns. ${ }^{21}$ Importantly, dispositional mindfulness is associated with greater activation in PFC and greater deactivation of amygdala during affect labeling (Figure 2). ${ }^{5}$ Conversely, mindfulness training leads to a stronger coupling of medial PFC and insula connectivity. ${ }^{22}$

A related set of research ${ }^{23,24}$ has focused on electrophysiological and imaging correlates of meditative and hypnotic states. Such studies have highlighted the role of limbic regions involved in control of autonomic responses and in interoceptive awareness. ${ }^{25-28}$ In addition, skilled meditators have (inconsistently) differential activation of anterior cingulate and adjacent medial frontal cortex ${ }^{29,30}$ and increased gray matter concentration in the insula. ${ }^{31}$ Furthermore, medi- tation appears to be associated with increased striatal dopamine release (Figure 3). ${ }^{32}$

It has been suggested that mindfulnessbased stress reduction may lead to a range of health benefits. ${ }^{4}$ Consistent with this are findings that mindfulness may have positive effects on the hypothalamic-pituitary-adrenal axis, and on various hormonal and immunological systems. ${ }^{33,34}$ Mindfulness-based interventions have led to changes in brain electrical activity ${ }^{35}$ (increased left-sided anterior activation), affective and cognitive changes, ${ }^{36-38}$ and increases in antibody titres to influenza vaccine. ${ }^{35}$ It is also notable that the neuronal correlates of dispositional and trained mindfulness are reminiscent of those seen during pain control, placebo response, and empathy. ${ }^{5,39-41}$

\section{Gene/Environment}

Interpersonal differences in mindfulness may well be influenced by genes and environments. ${ }^{42}$ Catechol-O-methyltransferase, the major enzyme determining cortical dopamine flux, has a com-

\section{FIGURE 1. \\ On $f M R I$, activation of RVLPC was increased during affect labeling compared with gen- der labeling ${ }^{18}$}

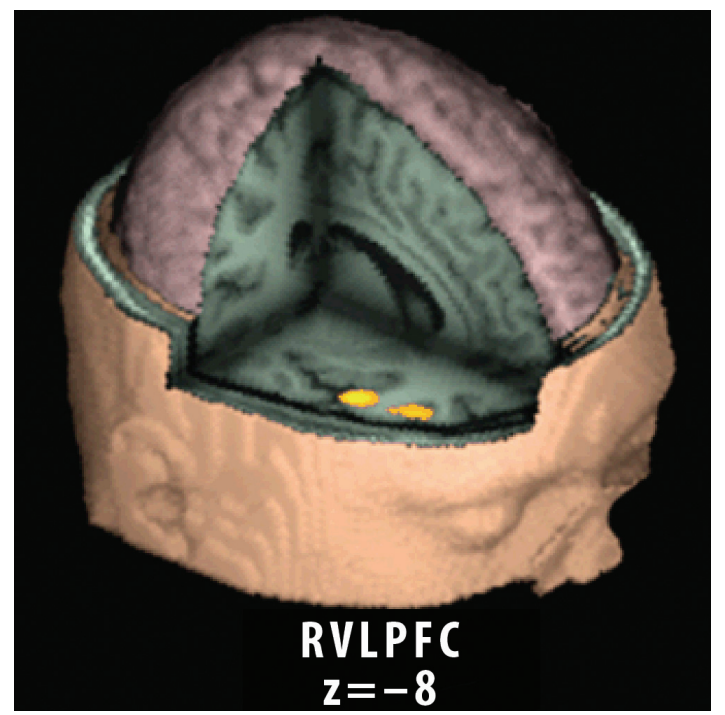

$\mathrm{fMRI}=$ functional magnetic resoance imaging; RVLPFC=right ventrolateral prefrontal cortex.

Lieberman MD, Eisenberger NI, Crockett MJ, Tom SM, Pfeifer JH, Way BM. Putting feelings into words: affect labeling disrupts amygdala activity in response to affective stimuli. Psychol Sci. 2007;18:421-428. Reprinted with permission. Copyright 2007.

Stein DJ, Ives-Deliperi V, Thomas KGF. CNS Spectr. Vol 13, No 9. 2008. 
mon functional polymorphism, val(158) met. In one study, ${ }^{43}$ the met allele was associated with heightened reactivity and increased connectivity in corticolimbic circuits in response to negative emotion. In another study, controls had the expected activation of RVLPFC and deactivation of amygdala when labeling emotions, while those exposed to early adversity (in the form of harsh parenting) had a positive correlation between RVLPFC and amygdala activation. ${ }^{44}$

\section{Evolutionary Approaches}

Clearly emotional regulation including mindfulness can be adaptive. Nevertheless, particular setpoints for mindfulness may be useful in particular contexts. In most circumstances, a judicious use of emotion, with careful integration of reason and passion, is a successful strategy. However, in certain situations, for example, when there are fewer resources, it may be hypothesized that a "live hard-die young" strategy, perhaps characterized by less empathy, ${ }^{45}$ is more successful. ${ }^{46}$ Speculatively, it is possible that emotional suppression or alexithymia can also be useful in certain contexts.

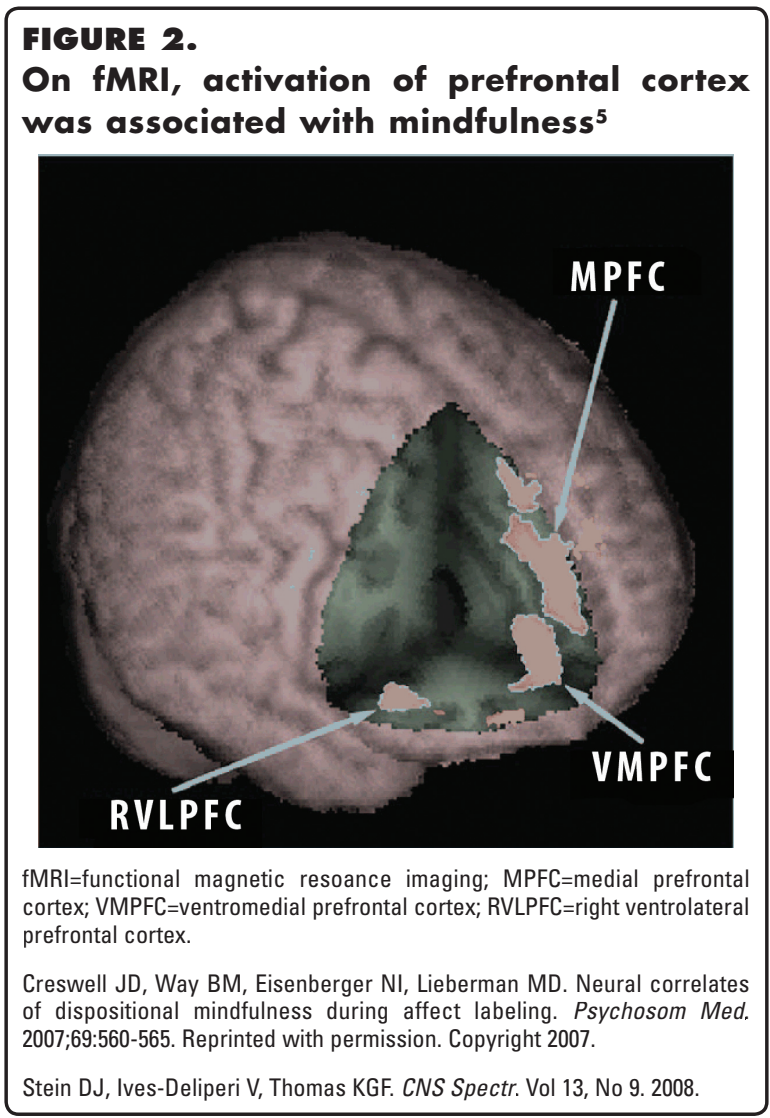

\section{CLINICAL IMPLICATIONS}

\section{DSM-IV-TR Diagnosis}

Emotional regulation is disrupted in a range of conditions, including the impulse-control disorders and certain personality disorders (eg, borderline personality disorder), and anxiety and mood disorders. Nevertheless, there is less work on the association of dispositional mindfulness with different categories of psychopathology. Similarly, while neural correlates of emotional regulation have been explored in a broad range of psychopathology, ${ }^{47}$ there is little work focusing specifically on correlates of mindfulness. Ultimately, a more detailed understanding of emotional dysregulation, including variations in mindfulness, may influence nosology.

\section{Assessment/Evaluation}

Mindfulness covers a range of different phenomena. ${ }^{1-3,48,49}$ Not surprisingly, therefore, a number of different measures are available. ${ }^{50-54}$ The labeling subscale of one mindfulness measure was associated with higher life satisfaction and better emotion regulation. ${ }^{53}$

\section{Pharmacotherapy/Psychotherapy}

While some believe that acceptance and commitment therapy (ACT) represents a third wave of cognitive-behavioral therapy (CBT), ${ }^{55}$ others emphasize that mindfulness is a core process across psychotherapies. ${ }^{56}$ Hofmann and Asmundson ${ }^{8}$ have argued that CBT pro-

\section{FIGURE 3. \\ [']C-raclopride binding potential images in a participant during (A) attention and (B) meditation ${ }^{32^{*}}$}
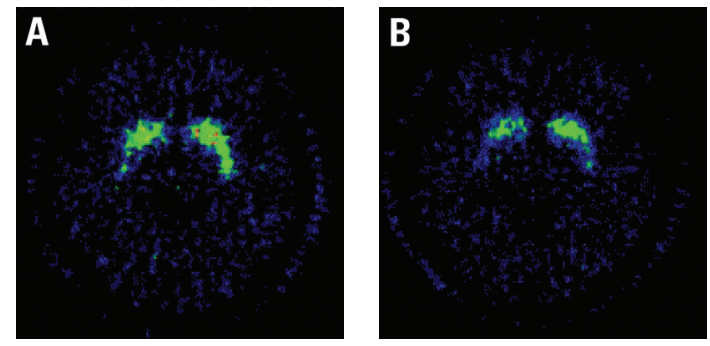

Reduced ["]C-raclopride binding potential in ventral striatum is evidence of increased endogenous dopamine release during meditation. ${ }^{32}$

Kjaer TW, Bertelsen C, Piccini P, Brooks D, Alving J, Lou HC. Increased dopamine tone during meditation-induced change of consciousness. Brain Res Cogn Brain Res. 2002;13:255-259. Reprinted with permission. Copyright 2002.

Stein DJ, Ives-Deliperi V, Thomas KGF. CNS Spectr. Vol 13, No 9. 2008. 
motes adaptive antecedent-focused emotional regulation strategies by focusing on reappraisal, while ACT primarily targets maladaptive response-focused strategies. The goal of ACT is to discourage suppression and experiential avoidance, which is the unwillingness to experience negatively evaluated sensations, feelings, and thoughts. ${ }^{57}$

Arguably, acceptance and mindfulness-based strategies counter suppression and thereby alleviate short-term distress, while the cognitive-restructuring techniques used in CBT may provide skills for enduring change. ${ }^{8}$ Mindfulnessbased stress reduction employs mindfulness meditation and has been studied in a range of conditions, including borderline personality disorder, depression, anxiety disorders, insomnia, and pain. ${ }^{4,58,59}$ Although not all outcomes are persuasive ${ }^{60}$ studies of mindfulness-based cognitive therapy for depression have been positive. ${ }^{61,62}$ Mindfulness interventions are possibly helpful for psychotherapists in treating their patients. ${ }^{63}$ Mindfulness traits may also be a predictor of treatment outcome..$^{64}$

\section{CONCLUSION}

Mindfulness is a construct that is rooted in the body; it involves attention to sensations and feelings, and its brain basis is gradually being delineated. There is ongoing debate, however, about whether mindfulness-based interventions represents a new wave of CBT or a core process in all psychotherapies. It has been argued ${ }^{8}$ that different CBT techniques act on different aspects of emotional regulation, with ACT helping to address strategies such as suppression and avoidance. Ongoing research on how mindfulness-based interventions alter psychobiology is contributing to the understanding of the neurobiology of CBT. CNS

\section{REFERENCES}

1. Grossman P. On measuring mindfulness in psychosomatic and psychological research. J Psychosom Res. 2008;64:405-408.

2. Bishop SR, Lau M, Shapiro S, et al. Mindfulness: a proposed operational definition. Clin Psychol Sci Pract. 2004;11:230-241

3. Baer RA, Smith GT, Hopkins J, Krietemeyer J, Toney L. Using self-report assessment methods to explore facets of mindfulness. Assessment. 2006;13:27-45.

4. Grossman P, Niemann L, Schmidt S, Walach H. Mindfulness-based stress reduction and health benefits. A meta-analysis. J Psychosom Res. 2004;57:35-43.

5. Creswell JD, Way BM, Eisenberger NI, Lieberman MD. Neural correlates of dispositional mindfulness during affect labeling. Psychosom Med. 2007;69:560-565.

6. Gross JJ. Antecedent- and response-focused emotion regulation: divergent consequences for experience, expression, and physiology. J Pers Soc Psychol. 1998; 74:224-237.

7. Gross JJ. Emotion regulation: affective, cognitive, and social consequences. Psychophysiology. 2002;39:281-291.
8. Hofmann SG, Asmundson GJ. Acceptance and mindfulness-based therapy: new wave or old hat? Clin Psychol Rev, 2008;28:1-16.

9. Teasdale JD, Segal ZV, Williams JM, Ridgeway VA, Soulsby JM, Lau MA. Prevention of relapse/recurrence in major depression by mindfulness-based cognitive therapy. J Consult Clin Psychol. 2000;68:615-623.

10. Lutz A, Slagter HA, Dunne JD, Davidson RJ. Attention regulation and monitoring in meditation. Trends Cogn Sci. 2008;12:163-169.

11. Shapiro SL, Carlson LE, Astin JA, Freedman B. Mechanisms of mindfulness. J Clin Psychol. 2006;62:373-386.

12. Stein DJ. Emotional regulation: implications for the psychobiology of psychotherapy. CNS Spectr. 2008;13:195-198.

13. Milad MR, Quirk GJ. Neurons in medial prefrontal cortex signal memory for fear extinction. Nature. 2002;420:70-74.

14. Johnstone T, van Reekum CM, Urry HL, Kalin NH, Davidson RJ. Failure to regulate: counterproductive recruitment of top-down prefrontal-subcortical circuitry in major depression. J Neurosci. 2007;27:8877-8884.

15. Ochsner KN, Gross JJ. The cognitive control of emotion. Trends Cogn Sci. 2005:9:242-249

16. Herwig U, Baumgartner T, Kaffenberger T, et al. Modulation of anticipatory emotion and perception processing by cognitive control. Neuroimage. 2007;37:652-662

17. Stein DJ. What is the self? A psychobiological perspective. CNS Spectr. 2007:12:333-336.

18. Lieberman MD, Eisenberger NI, Crockett MJ, Tom SM, Pfeifer JH, Way BM. Putting feelings into words: affect labeling disrupts amygdala activity in response to affective stimuli. Psychol Sci. 2007;18:421-428

19. Lieberman MD, Hariri A, Jarcho JM, Eisenberger NI, Bookheimer SY. An fMRI investigation of race-related amygdala activity in African-American and CaucasianAmerican individuals. Nat Neurosci. 2005;8:720-722.

20. Hariri AR, Bookheimer SY, Mazziotta JC. Modulating emotional responses: effects of a neocortical network on the limbic system. Neuroreport. 2000;11:43-48.

21. Urry HL, van Reekum CM, Johnstone T, et al. Amygdala and ventromedial prefrontal cortex are inversely coupled during regulation of negative affect and predict the diurnal pattern of cortisol secretion among older adults. J Neurosci, 2006;26:4415-4425.

22. Farb NA, Segal ZV, Mayberg H, et al. Attending to the present: mindfulness meditation reveals distinct neural modes of self-reference. Soc Cogn Affect Neurosci. 2007:2:313-322

23. Newberg AB, Iversen J. The neural basis of the complex mental task of meditation: neurotransmitter and neurochemical considerations. Med Hypotheses. 2003;61:282-291.

24. Vermetten E, Douglas Bremner J. Functional brain imaging and the induction of traumatic recall: a cross-correlational review between neuroimaging and hypnosis. Int J Clin Exp Hypn. 2004;52:280-312.

25. Kakigi R, Nakata $H$, Inui $K$, et al. Intracerebral pain processing in a Yoga Master who claims not to feel pain during meditation. Eur J Pain. 2005;9:581-589.

26. Cahn BR, Polich J. Meditation states and traits: EEG, ERP, and neuroimaging studies. Psychol Bull. 2006;132:180-211.

27. Lutz A, Brefczynski-Lewis J, Johnstone T, Davidson RJ. Regulation of the neural circuitry of emotion by compassion meditation: effects of meditative expertise. PLOS ONE 2008;3:e1897.

28. Lazar SW, Bush G, Gollub RL, Fricchione GL, Khalsa G, Benson H. Functional brain mapping or the relaxation response and meditation. Neuroreport. 2000;11:1581-1585.

29. Hölzel BK, Ott U, Hempel H, et al. Differential engagement of anterior cingulate and adjacent medial frontal cortex in adept meditators and non-meditators. Neurosci Lett. 2007;421:16-21.

30. Brefczynski-Lewis JA, Lutz A, Schaefer HS, Levinson DB, Davidson RJ. Neura correlates of attentional expertise in long-term meditation practitioners. Proc Nat/ Acad Sci U S A. 2007;104:11483-11488.

31. Hölzel BK, Ott U, Gard T, et al. Investigation of mindfulness meditation practitioners with voxel-based morphometry. Soc Cogn Affect Neurosci. 2008;3:55-61.

32. Kjaer TW, Bertelsen C, Piccini P, Brooks D, Alving J, Lou HC. Increased dopamine tone during meditation-induced change of consciousness. Brain Res Cogn Brain Res. 2002;13:255-259.

33. O'Loughlin RE, Zuckerman M. Mindfulness as a moderator of the relationship between dehydroepiandrosterone and reported physical symptoms. Pers Individ Dif. 2008;44:1193-1202.

34. Carlson LE, Speca M, Faris P, Patel KD. One year pre-post intervention follow-up of psychological, immune, endocrine and blood pressure outcomes of mindfulnessbased stress reduction (MBSR) in breast and prostate cancer outpatients. Brain Behav Immun. 2007;21:1038-1049.

35. Davidson RJ, Kabat-Zinn J, Schumacher J, et al. Alterations in brain and immune function produced by mindfulness meditation. Psychosom Med. 2003;65:564-570.

36. Chambers R, Lo BC, Allen NB. The impact of intensive mindfulness training on attentional control, cognitive style, and affect. Cognit Ther Res. 2008;32:303-322.

37. Arch JJ, Craske MG. Mechanisms of mindfulness: emotion regulation following a focused breathing induction. Behav Res Ther. 2006;44:1849-1858. 
38. Ortner CN, Kilner SJ, Zelazo PD. Mindfulness meditation and reduced emotional interference on a cognitive task. Motiv Emot. 2007:31:271-283.

39. Stein DJ, van Honk J, Ipser J, Solms M, Panksepp J. Opioids: from physical pain to the pain of social isolation. CNS Spectr. 2007;12:669-670,672-674.

40. Stein DJ, Mayberg H. Placebo: the best pill of all. CNS Spectr. 2005;10:440-442.

41. Stein DJ. Empathy: at the heart of the mind. CNS Spectr. 2005;10:280-283.

42. Michal M, Beutel ME, Jordan J, Zimmermann M, Wolters S, Heidenreich T. Depersonalization, mindfulness, and childhood trauma. J Nerv Ment Dis. 2007;195:693-696.

43. Drabant EM, Hariri AR, Meyer-Lindenberg A, et al. Catechol 0-methyltransferase val158met genotype and neural mechanisms related to affective arousal and regulation. Arch Gen Psychiatry. 2006;63:1396-1406.

44. Taylor SE, Eisenberger NI, Saxbe D, Lehman BJ, Lieberman MD. Neural responses to emotional stimuli are associated with childhood family stress. Biol Psychiatry, 2006;60:296-301.

45. Block-Lerner J, Adair C, Plumb JC, Rhatigan DL, Orsillo SM. The case for mindfulness-based approaches in the cultivation of empathy: does nonjudgmental, present-moment awareness increase capacity for perspective-taking and empathic concern? J Marital Fam Ther. 2007;33:501-516.

46. Higley JD, Mehlman PT, Higley SB, et al. Excessive mortality in young free-ranging male non-human primates with low cerebrospinal fluid 5-hydroxyindolacetic acid concentrations. Arch Gen Psychiatry. 1996;53:537-543.

47. Taylor SF, Liberzon I. Neural correlates of emotion regulation in psychopathology. Trends Cogn Sci. 2007;11:413-418.

48. Brown KW, Ryan RM. Perils and promise in defining and measuring mindfulness: Observations from experience. Clin Psychol Sci Pract. 2004;11:242-248.

49. Rosch E. More than mindfulness: when you have a tiger by the tail, let it eat you. Psychol Inq. 2007;18:258-264.

50. Lau MA, Bishop SR, Segal ZV, et al. The Toronto Mindfulness Scale: development and validation. J Clin Psychol. 2006:62:1445-1467.

51. Walach H, Buchheld N, Buttenmuller V, Kleinknecht N, Schmidt S. Measuring mindfulness: the Freiburg Mindfulness Inventory (FMI). Pers Individ Dif. 2006;40:1543-1555.
52. Cardaciotto L, Herbert JD, Forman EM, Moitra E, Farrow V. The assessment of present-moment awareness and acceptance: The Philadelphia Mindfulness Scale. Assessment. 2008;15:204-223.

53. Baer RA, Smith GT, Allen KB. Assessment of mindfulness by self-report: the Kentucky inventory of mindfulness skills. Assessment. 2004;11:191-206.

54. Feldman G, Hayes A, Kumar S, et al. Mindfulness and emotion regulation: the development and initial validation of the Cognitive and Affective Mindfulness Scale-Revised (CAMS-R). J Psychopathol Behav Assess. 2007;29:177-190

55. Hayes SC. Acceptance and commitment therapy, relational frame theory, and the third wave of behavioral and cognitive therapies. Behav Ther, 2004;35:639-665.

56. Martin JR. Mindfulness: a proposed common factor. Journal of Psychotherapy Integration. 1997;7:291-312

57. Hayes SC, Luoma JB, Bond FW, Masuda A, Lillis J. Acceptance and commitment therapy: model, processes and outcomes. Behav Res Ther. 2006;44:1-25.

58. Brown KW, Ryan RA, Creswell JD. Mindfulness: theoretical foundations and evidence for its salutary effects. Psychol Inq. 2007;18:211-237.

59. Ivanovski B, Malhi GS. The psychological and neurophysiological concomitants of mindfulness forms of meditation. Acta Neuropsychiatrica. 2007;19:76-91.

60. Toneatto T, Nguyen L. Does mindfulness meditation improve anxiety and mood symptoms? A review of the controlled research. Can J Psychiatry. 2007;52:260-266

61. Coelho HF, Canter PH, Ernst E. Mindfulness-based cognitive therapy: evaluating current evidence and informing future research. J Consult Clin Psychol. 2007;75:1000-1005.

62. Allen NB, Blashki G, Gullone E. Mindfulness-based psychotherapies: a review of conceptual foundations, empirical evidence and practical considerations. Aust N Z $J$ Psychiatry. 2006; 40:285-294

63. Grepmair L, Mitterlehner F, Loew T, Bachler E, Rother W, Nickel M. Promoting mindfulness in psychotherapists in training influences the treatment results of their patients: a randomized, double-blind, controlled study. Psychother Psychosom. 2007:76:332-338.

64. Masicampo EJ, Baumeister RR. Relating mindfulness and self-regulatory processes. Psychol Inq. 2007:18:255-258. 